\title{
University Students' Career Choice and Emotional Well-Being
}

\section{Mingming Zhou}

University of Macau

\section{Yabo Xu}

Sun Yat-sen University

\section{Doi:10.5901/jesr.2013.v3n7p243}

\begin{abstract}
The impact of emotional well-being on one's career choice has received insufficient attention. There are both conceptual and empirical reasons to expect a positive relationship, but there is a lack of evidence directly testing this proposition. This study surveyed 137 Chinese university students' life happiness, satisfaction and hope, as well as their career decision-making. Results showed that students who reported to be more satisfied and more hopeful in their life in general were more decisive in their career choice, more aware of their strengths and weaknesses, more knowledgeable about their future career, and more acknowledged the importance of their career. As such a call is made for more research on relevant factors in the career decision-making process and implications of the potentially important relationship between one's career choice and emotional well-being.
\end{abstract}

\section{Introduction}

Young adults today are faced with one important developmental task which is to begin the process of making career decisions. When they first enter the university, they need to decide what major field of study to select. This is expected to lead to the occupation they wish to pursue after graduation. However, many young adults report facing difficulties in making career decisions (Gati et al., 2011). These difficulties may stem from a variety of sources, including lack of readiness, lack of information, and inconsistent information (Gati, Krausz, \&Osipow, 1996). Hence, individuals who have difficulties making career decisions may have unclear goals, insufficient knowledge about possible alternative choices, lower motivation to make a choice, or may be indecisive.

Substantial research has been conducted in Western contexts which investigated certain intrapersonal and contextual factors relating to career decision-making. It is unknown whether the identified factors have a similar impact on individuals with collectivism-oriented cultural values (Brown, 2002; Leong \& Hardin, 2002). The present study seeks to report on important career-related and intra-individual variables associated with career decision-making in Chinese university students. We presented a brief review of the difficulties in making career decisions to provide the context for the design and predictions of the present study.

\section{Career decision-making}

Making a career decision is a complex process (Gati et al., 1996). From a cognitive-behavioral perspective, career decision-making is a problem-solving process when choosing between occupational alternatives (Bethencourt \& Cabrera, 2011). In order to make better decisions, individuals need to distinguish between more important and less important decisions, make more effort in the former with adaptive goals, recognize resolution options, and select the one thatwillachieve desired outcomes (Byrnes, 2002). An emerging body of theory and research suggests that career decision-making is often accompanied by psychological and emotional well-being. Research in the United States has found a positive correlation between emotions and career decision-making, including greater capacity to manage one's own emotional response to this process (Emmerling\&Cherniss, 2003) as well as trust in one's capacity to confront career decision-making tasks (Brown,George, \& Smith, 2003). Further, difficulties in career decision making are found to be associated with psychological distress and low levels of well-being (Fouad et al., 2006). The current study will focus on the latter perspective, that is, how one's emotional well-being is relevant to career choice.

During career decision-making process, career decidedness/indecision has received the most attention which is 
concerned with the difficulties preventing individuals from making a career decision (Kelly \& Lee, 2005; Santos, 2001).Some individuals are labeled as undecided who experience only temporary or developmental career decisionmaking difficulties, while others are considered as indecisive who suffer from more chronic and pervasive difficulties, due to emotional or personality-related reasons (Kelly \&Pulver, 2003; Meldahl\&Muchinsky, 1997; Osipow, 1999). This could include the lack of information needed to make a decision, the lack of clear sense of self as to what type of occupations are suitable, the lack of motive to think it through, the lack of recognition of the importance of career, and etc.

Previous studies found that career indecision is associated with different emotional and personality factors (e.g., Fuqua, Blum, \& Hartman, 1988; Santos, 2001; Saunders, Peterson, Sampson, \& Reardon, 2000). In particular, negative intra-individual variables have been linked with individuals who report significantly higher levels of career indecision (Kelly \& Lee, 2002). These include a negative affective disposition (Multon, Heppner,\&Lapan, 1995), anxiety (Germeijs, Verschueren, \&Soenens, 2006), fear of success (Staley, 1996) and lower self-esteem (Creed,Prideaux, \& Patton, 2005; Germeijs\& De Boeck, 2002, 2003; Staley, 1996). Saka, Gati, and Kelly (2008) explored relevant personality and emotional factors in their model, and identified three major sources of problems - pessimistic views, anxiety, and selfconcept/identity. Specifically, individuals who hold pessimistic views are more pessimistic about the career decisionmaking process, the occupation per se, or their control over the process, the choice, or the outcomes. Those who feel more anxious were generally undecided and indecisive about the career choice. Also, those with a sense of low selfworth have difficulties in formulating clear vocational preferences, interests, aspirations, and career goals.

\section{The Current Study}

Although current literature suggests that a variety of emotional factors are involved in career decision-making, which may facilitate or hinder this process, only a few studies are available that investigate how positive emotional well-being relates tocareer choice. The general finding is that higher levels of career indecision appear to be associated with lower life satisfaction (Creed et al., 2005; Skorikov, 2007). No studies have examined how one's hope for life relates to career decisions. The present study set out to extend this evidence base by examining positive components such as life satisfaction and hope in young adults using a cross-sectional research design. This body of work will attest to and add to the myriad of variables that have been explored so far to build a clearer emotional profile of decided and undecided individuals. The goal of the current study is thus to further investigate how individual emotional well-being, as reflected by the level of life satisfaction and hope, is associated with his or her career decision-making process. More specifically, four types of reasons for making (in)effective career decisions (lack of self-clarity, lack of occupational-educational information, lack of decisiveness, and career choice importance) and two intra-individual variables (life satisfaction, hope) were examined in this study. The followinghypotheses were tested:

1. Students will experience lessdifficulty in career decision-making if they feel more satisfied with their life in general;

2. Students will experience less difficulty in career decision-making if they have more hope for their life in general.

\section{Methods}

\subsection{Participants and Procedure}

One hundred and thirty-seven freshmen $(74.5 \%$ male) who were enrolled in the computer programming course offered at a Chinese university participated in this study. They ranged in age from 16 to 20 years $(M=18.65, S D=.85)$. Participants were provided with a questionnaire package on hardcopies at the beginning of the session in the middle of the semester. The package contained a demographics questionnaire, Hope Scale (Snyder et al., 1991), Satisfaction with Life Scale (Diener, Emmons, Larsen, \& Griffin, 1985), and Career Decision Profile (Jones, 1989). The researcher briefed the participants about the purpose of this study and assured the confidentiality of their responses and personal information. The questionnaire packages were immediately collected after they were completed. For the present study, all the scales were translated into Chinese, and the back-translation revealed semantically similar items with the original scales. 


\subsection{Measures}

The 8-item Hope Scale (Snyder et al., 1991) was used to assess one's affirmative beliefs about his or her ability to accomplish personal goals. It comprised the 4-item Agency subscale (e.g., "I energetically pursue my goals".) and the 4item Pathways subscale (e.g., "There are lots of ways around any problem".). Both subscales were reported with adequate internal reliability (Snyder et al., 1991). All eight items c be summed to produce a total hope score, mirroring the model of hope as a higher-order latent construct consisting of the Agency and Pathways beliefs. Items were scored on a 7-point scale from 1 (strongly disagree) to 7 (strongly agree). Higher scores indicated stronger endorsement of the construct. Cronbach's alpha for this scale in the current study was .69.

Satisfaction with Life Scale (SWLS; Diener et al., 1985) assessed global life satisfaction with five statements with regards to quality of life. Participants indicated the extent to which they agreed with each item on a 7-point Likert scale ranging from "strongly disagree" to "strongly agree". A sample item is: "The conditions of my life are excellent". Higher scores indicated greater life satisfaction. Research has established acceptable psychometric properties for the SWLS both in Western (e.g., Diener et al., 1985;Lucas, Diener, \& Suh, 1996; Pavot, Diener, Colvin, \& Sandvik, 1991; Pavot \& Diener, 1993) and Chinese samples (Bai, Wu, Zheng, \& Ren, 2011; Sachs, 2003; Wu \& Yao, 2006; Wu, Chen, \& Tsai, 2009). Cronbach's alpha for this scale in the current sample was .58.

The 24-item Career Decision Profile (CDP; Jones, 1988) measured career decision status, with three internally consistent subscales: decidedness, comfort, and reasons. The reasons subscale consisted of lack of self-clarity, lack of occupational-educational information, lack of decisiveness, and lack of career choice importance. A 7-point scale ranging from 1 (strongly disagree) to 7 (strongly agree) was used. The CDP has demonstrated reliability and convergent validity (Jones, 1989). To understand the relationship between one's emotional well-being toward reasons of career decision status, only thelack of self-clarity, lack of occupational-educational information,lack of decisiveness and career choice importance subscales were analyzed in this study. Cronbach's alpha values for lack of self-clarity, lack of occupational-educational information, lack of decisiveness, and career choice importance in the current sample were.47, .49 (with one item removed), .83,and .63,respectively.

\section{Results}

The descriptive statistics for all the variables are presented in Table 1. The students were in general neither too satisfied nor too dissatisfied with their life, as seen by its mean score $(M=3.70, S D=1.05)$ slightly above the middle score of the scale (3.50). However, they seemed to be more hopeful for life $(M=4.42, S D=.95)$. With regards to their career choice, the lack of required informationwas reported to be the top reason for career decision-making difficultly, followed by the lack of a clear sense of self, the lack of decisiveness and the recognition of career choice importance scored lowest.

Table 1.Descriptive statistics and zero-order correlations among primary variables $(\mathrm{N}=137)$

\begin{tabular}{|c|c|c|c|c|c|c|c|}
\hline & 1 & 2 & 3 & 4 & 5 & $\mathrm{M}$ & SD \\
\hline 1. Satisfaction & - & & & & & 3.70 & 1.05 \\
\hline 2. Hope & $.58^{\star \star}$ & - & & & & 4.42 & .95 \\
\hline 3. Lack of self-clarity & $-.32^{\star \star}$ & $-.43^{\star \star}$ & - & & & 4.03 & 1.24 \\
\hline 4. Lack of occupational-educational information & $-.33^{\star \star}$ & $-.48^{\star *}$ & $.78^{* *}$ & - & & 4.45 & 1.16 \\
\hline 5. Lack of decisiveness & $-.19 *$ & $-.32^{\star \star}$ & $.78^{\star *}$ & $.63^{\star \star}$ & - & 3.58 & 1.39 \\
\hline 6. Career choice importance & $.51^{\star \star}$ & $.38^{\star \star}$ & $-.53^{\star \star}$ & $-.37 * \star$ & $-.22^{*}$ & 3.49 & 1.29 \\
\hline
\end{tabular}

${ }^{*} p<.05 ;{ }^{* *} p<.01$

The zero-order correlations among these variables (see Table 1) showed that life satisfaction significantly negatively correlated with lack of self-clarity $(r=-.32, p<.01)$, lack of information $(r=-.33, p<.01)$,lack of decisiveness $(r=-.19, p<$ $.05)$ but positively with career choice importance $(r=.51, p<.01)$. Similarly, hope significantly positively correlated with career choice importance $(r=.38, p<.01)$, but significantly negatively correlated with lack of self-clarity $(r=-.43, p<.01)$, lack of information $(r=-.48, p<.01)$ and lack of decisiveness $(r=-.32, p<.01)$. It seemed that if one was more satisfied with or hopeful for life, he or she would have a clearer sense of self and more knowledge about the occupation information, acknowledge more the importance of career and be more decisive in decision-making.

Next, simultaneous regression analysis was run to better understand the contribution of the two emotional variables to career choice. As shown in Table 2 , life satisfaction significantly negatively predicted lack of self-clarity $(\beta=$ $.47, p<.001)$, lack of career-related information $(\beta=-.23, p<.05)$, but positively predicted career choice importance $(\beta=$ 
$.60, p<.001)$. A somewhat different pattern was observed for hope. Hope significantly negatively predicted lack of information $(\beta=-.35, p<.001)$ and lack of decisiveness $(\beta=-.25, p<.05)$.

Table 2. Beta-coefficients of multiple regressions testing the relations of emotional well-being to career decision-making variables

\begin{tabular}{ccccc}
\hline DV & $\begin{array}{c}\text { Lack of self- } \\
\text { clarity }\end{array}$ & $\begin{array}{c}\text { Lack of occupational- } \\
\text { educational information }\end{array}$ & Lack of decisiveness & $\begin{array}{c}\text { Career choice } \\
\text { importance }\end{array}$ \\
\hline df & $(2,112)$ & $(2,125)$ & $(2,125)$ & $(2,120)$ \\
Satisfaction & $-.47^{\star \star *}$ & $-.23^{*}$ & -.12 & $.60^{\star \star *}$ \\
Hope & -.16 & $-.35^{\star \star *}$ & $-.25^{\star}$ & .04 \\
\hline${ }^{*} p<.05 ;{ }^{* \star} p<.001$ & & & &
\end{tabular}

\section{Discussion and Conclusion}

Generally, research on career decision-making and positive emotions has been extremely limited. The present study adds to the literature by seeking to clarify whether young adults' positive emotional well-being is associated with their career decision-making. In general, the findings highlighted that career decision-making in Chinese young people was related to their emotional well-being, as reflected in their life satisfaction and hope.

Although hope and life satisfaction were both related to the difficulties to make career decisions, life satisfaction was found to be a significant predictor of self-clarity, career importance as well as access to occupational-educational information, whereas hope negatively predicted the lack of occupational-educational information and career indecisiveness. The former finding indicated that individuals who are more satisfied with life in general know more about themselves, acknowledge the importance of career, and have more access to the information they need to make a career decision.People's self-knowledge forms through experience with and interpretation of one's environment and is influenced by evaluations of others, reinforcements, and attributions of one's own behavior (Wehmeyer, 1996). When the judgment of self is evaluative, individuals' affective reactions are even more relevant (Levine, Wyer, \& Schwarz, 1994). Suh (2002) found across cultures those whose self-beliefs are clearly and confidently defined were significantly more likely to experience higher life satisfaction. The current findings also lend support to the claim that such affective reactions can be used as a basis for a range of judgments, such as career decisions.

Related to self-clarity is the means to achieve one's career goals. Seeking relevant information is one of the major means. Literature shows that individuals with information deficits are not really seeking out more options (Miller \& Brown, 2005), but rather to decide between several options (Brown \& Rector, 2008). With the collection of relevant information, the level of satisfaction with the career, or life in general, will be increased too.

What a career choice means varies across individuals. Our results showed that if an individual feels more content with what life provides to him or her, he or she would be more likely to see the value of making a wise career decision. Past research also suggests that people who are more enthusiastic about their career tend to report to be more satisfied with their life (Bonebright, Clay, \& Ankenmann, 2000).

The finding that hope negativelypredicted the lack of occupational-educational information and decisiveness suggests that individuals who report to be more hopeful are prone to have less difficulty in seeking career-related information and be more decisive in their decision-making process. Intuitively, when one has more hope for his or her life, he or she is more likely to seek appropriate means to fulfill the hope. Seeking occupational-educational information is such a means through which individuals are able to collect required information to make a decision accordingly. This, in turn, reduces the indecisiveness in their decision-making.

The findings of this study are subject to some limitations. First, self- report instruments were used to measure all the variables. Self-report instruments may be susceptible to social desirability biases, thereby limiting the validity of conclusions that can be drawn with self-reported measures (Zhou \& Winne, 2012). Related to this is the relatively lowinternalconsistency (less than .50) in the subscales of the lack of self-clarity and lack of occupational-educational information subscales. This limits the interpretation of our findings to some extent, but also suggests the need to develop indigenouscareer scales to further investigate this constructamong the Chinese people. Further, as hope and satisfaction exhibited different patterns in predicting career choice variables, it is not clear at this point how different emotions function in influencing one's career decision-making process. This warrants future investigations.

Identifying the unique difficulties that prevent individuals from reaching a career decision is an essential step in providing them with the help they need (Gati et al., 1996). In light of these limitations, our findings could be helpful in the 
design of career interventions. First, career interventions for improving one's emotional well-being (e.g., views/perceptions about life) might enhance the career decision-making process in terms of a clearer self-knowledge, more access to career-related information, and seeing more value of having a career. Second, there is a need to consider one's emotion, given the direct effects of hope and satisfaction on the career decisiveness and reasons for indecisiveness. Therefore, it is suggested that interventions should provide activities to promote generalized positive emotions, and create effective means to achieve career goals.

\section{Reference}

Bai, X., Wu, C., Zheng, R., \&Ren, X. (2011).The psychometric evaluation of the Satisfaction with Life Scale using a nationally representative sample of China.Journal of Happiness Studies, 12, 183-197.

Bethencourt, J., \& Cabrera, L. (2011).Personality and career decision making in undergraduates.e-Journal of Educational Research, Assessment and Evaluation, 17(1), article 4

Bonebright, C. A., Clay, D. L., \&Ankenmann, R. D. (2000).The relationship of workaholism with work-life conflict, life satisfaction, and purpose in life.Journal of Counseling Psychology, 47, 469-477.

Brown, D. (2002). The role of work and cultural values in occupational choice, satisfaction, and success: A theoretical statement. Journal of Counseling and Development, 80, 48-56.

Brown, C., George, C. R., \& Smith, M. L. (2003). The role of Emotional Intelligence in the career commitment and decision-making process.Journal of Career Assessment, 11, 379-392.

Brown, S. D., \& Rector, C. C. (2008). Conceptualizing and diagnosing problems in vocational decision-making. In S. D. Brown \& R. W. Lent (Eds.), Handbook of counseling psychology (4th ed., pp. 392-407). New York: Wiley.

Byrnes, J. P. (2002). The development of decision-making.Journal of Adolescent Health, 31, 208-215.

Creed, P., Prideaux, L. A., \& Patton, W. (2005).Antecedents and consequences of career decisional states in adolescence.Journal of Vocational Behavior, 67, 397-412.

Diener, E., Emmons, R. A., Larsen, R. J., \& Griffin, S. (1985). The Satisfaction with Life Scale.Journal of Personality Assessment, 49, 71-75.

Emmerling, R. J., \&Cherniss, G. (2003).Emotional intelligence and the career choice process.Journal of Career Assessment, 11, 153167.

Fouad, N. A., Guillen, A., Harris-Hodge, E., Henry, C., Novakovic, A., Terry, S., \&Kantamneni, N. (2006).Need, awareness, and use of career services for college students.Journal of Career Assessment, 14, 407-420.

Fuqua, D. R., Blum, C. R., \& Hartman, B. W. (1988). Empirical support for the differential diagnosis of career indecision.Career Development Quarterly, 36, 364-373.

Gati, I., Gadassi, R., Saka, N., Hadadi, Y., Anserbergn N., Friedmann, \&Asulin-Peretz, L. (2011). Emotional and personality-related aspects of career decision-making difficulties: Facets of career indecisiveness. Journal of Career Assessment, 19, 3-20.

Gati, I., Krausz, M., \&Osipow, S. H. (1996).A taxonomy of difficulties in career decision-making. Journal of Counseling Psychology, 43, 510-526.

Germeijs, V., \& De Boeck, P. (2002).A measurement scale for indecisiveness and its relationship to career indecision and other types of indecision.EuropeanJournal of Psychological Assessment, 18(2), 113-122.

Germeijs, V., \& De Boeck, P. (2003). Career indecision: Three factors from decision theory. Journal of Vocational Behavior, 62, 11-25.

Germeijs, V., Verschueren, K., \&Soenens, B. (2006). Indecisiveness and high school students' career decision-making process: Longitudinal associations and the mediational role of anxiety. Journal of Counseling Psychology, 53, 397-410.

Jones, L. K. (1989). Measuring a three-dimensional construct of career indecision among college students: A revision of the vocational decision scale-the career decision profile.Journal of Counseling Psychology, 36, 477-486.

Kelly, K. R., \& Lee, W. C. (2002).Mapping the domain of career decision problems.Journal of Vocational Behavior, 61, 302-326.

Kelly, K. R., \& Lee, W. C. (2005).Relations of psychological type to career indecision among university students.Journal of Psychological Type, 64, 11-20.

Kelly, K. R., \&Pulver, C. A. (2003). Refining measurement of career indecision types: A validity study. Journal of Counseling and Development, 81, 445-454.

Leong, F. T. L., \& Hardin, E. (2002). Career psychology of Asian Americans: Culture validity and culture specificity. In G.C.N. Hall \& S. Okazaki (Eds.), Asian American psychology: The science of live in context (pp. 131-152). American Psychology Association: Washington, DC.

Levine, S. R., Wyer Jr., R. S., \& Schwarz, N. (1994). Are you what you feel? The affective and cognitive determinants of selfjudgments. European Journal of Social Psychology, 24(1), 63-77.

Lucas, R. E., Diener, E., \&Suh, E. (1996).Discriminant validity of well-being measures.Journal of Personality and Social Psychology, 71 , $616-628$

Meldahl, J. M., \&Muchinsky, P. M. (1997). The neurotic dimension of vocational indecision: Gender comparability? Journal of Career Assessment, 5, 317-331.

Miller, M. J., \& Brown, S. D. (2005). Counseling for career choice: Implications for improving interventions and working with diverse populations. In S. D. Brown \& R. W. Lent (Eds.), Career development and counseling: Putting theory and research to work (pp. 
441-465). New York: Wiley.

Multon, K. D., Heppner, M. J., \&Lapan, R. T. (1995). An empirical derivation of career decision subtypes in a high school sample. Journal of VocationalBehavior, 47, 76-92.

Osipow, S. H. (1999). Assessing career indecision.Journal of Vocational Behavior, 55, 147-154.

Pavot, W., \&Diener, E. (1993).Review of the Satisfaction with Life Scale.Psychological Assessment, 5, 164-172.

Pavot, W., Diener, E., Colvin, C. R., \&Sandvik, E. (1991). Further validation of the satisfaction with life scale: Evidence for the crossmethod convergence of well-being measures. Journal of Personality Assessment, 57, 149-161.

Sachs, J. (2003). Validation of the satisfaction with life scale in a sample of Hong Kong university students.Psychologia, 46, 225-234.

Saka, N., Gati, I., \& Kelly, K. R. (2008).Emotional and personality-related aspects of career decision-making difficulties.Journal of Career Assessment, 16, 403-424.

Santos, P. J. (2001). Predictors of generalized indecision among Portuguese secondary school students.Journal of Career Assessment, 9, 381-396.

Saunders, D. E., Peterson, G. W., Sampson, J. P. Jr., \& Reardon, R. C. (2000). Relation of depression and dysfunctional career thinking to career indecision. Journal of Vocational Behavior, 56, 288-298.

Skorikov, V. B. (2007). Continuity in adolescent career preparation and its effects on adjustment.Journal of Vocational Behavior, 70, 824.

Snyder, C. R., Harris, C., Anderson, J. R., Holleran, S. A., Irving, L. M., Sigman, S. T. et al. (1991). The will and the ways: Development and validation of an individual differences measure of hope. Journal of Personality and Social Psychology, 60, 570-585.

Staley, W. (1996, Nov).The relationship between fear of success, self-concept, and career decision making. Paper presented at the Annual Meeting of the Mid-SouthEducational Research Association. Tuscaloosa, AL: EDRS.

Suh, E. M. (2002). Culture, identity consistency, and subjective well-being.Journal of Personality and Social Psychology, 83, 1378-1391.

Wehmeyer, M. L. (1996). Self-determination as an educational outcome: Why is it important to children, youth and adults with disabilities? In D.J. Sands \& M. L. Wehmeyer (Eds.), Self-determination across the life span: Independenceand choice for people with disabilities (pp. 17-36). Baltimore, MD: Paul H. Brookes.

Wu, C. H., \& Yao, G. (2006). Analysis of factorial invariance across gender in the Taiwan version of the satisfaction with life scale. Personality and Individual Differences, 40, 1259-1268.

Wu, C. H., Chen, L. H., \& Tsai, Y. M. (2009).Longitudinal invariance analysis of the Satisfaction with Life Scale.Personality and Individual Differences, 46, 396-401.

Zhou, M., \& Winne, P. H. (2012). Modeling academic achievement by self-reported versus traced goal orientation. Learning and Instruction, 22(6), 413-419. 